\title{
Chaunocephalus ferox (Digenea: Echinostomatidae) infection associated with fatal cachexia in a white stork (Ciconia ciconia)
}

\author{
M. SANTORO ${ }^{1 *}$, B. DEGLI UBERTI ${ }^{2}$, G. GALIERO $^{2}$, F. DI PRISCO $^{3}$, N. D$^{\prime}$ ALESSIO $^{3}$, V. VENEZIANO $^{4}$
}

\begin{abstract}
${ }^{1}$ Department of Public Health and Infectious Diseases, Section of Parasitology, Sapienza University of Rome, Piazzale Aldo Moro 5, 00185 Rome, Italy, *E-mail: marisant@libero.it, mariosantoro1@gmail.com; ${ }^{2}$ Istituto Zooprofilattico Sperimentale del Mezzogiorno, Via Salute n 9, Portici, Naples, Italy; ${ }^{3}$ Istituto Zooprofilattico Sperimentale del Mezzogiorno, Section of Avellino, Monteforte Irpino, Avellino, Italy; ${ }^{4}$ Department of Veterinary Medicine and Animal Production, University of Naples Federico II, Naples, Italy
\end{abstract}

\begin{abstract}
Summary
Post-mortem examination of a sub-adult debilitated white stork (Ciconia ciconia) from southern Italy showed nodular enteritis associated with massive infection by Chaunocephalus ferox (Digenea: Echinostomatidae). Pathological changes included lesions ranging from traumatic destruction of tissues with hemorrhages and thickness of mucosa and submucosa at fluke penetration site to loss of duodenal villi and necrosis. Lesions through the whole intestinal tract associated with the digenean infection were considered as compatible with causing the cachexia and death of the white stork.
\end{abstract}

Keywords: Ciconia ciconia; white stork; Chaunocephalus ferox; pathological changes; southern Italy

\section{Introduction}

The white stork (Ciconia ciconia) is a Palearctic migrant with a carnivorous opportunistic diet. In Europe its population declined rapidly and severely during the 1960 s but has recovered strongly over the past two decades. From February to August, southern Italy represents an important site for migratory and breeding individuals that move from Africa to north Europe (BirdLife International, 2012). Reasons for the decline have never been established with certainty, but habitat alteration, excessive use of pesticides, and collision and electrocution from overhead powerlines have been considered the main causes (BirdLife International, 2012). However it was suggested that the intestinal nodular lesions associated with Chaunocephalus ferox (Digenea: Echinostomatidae) infection could be a cause of debilitation and associated mortality in free-living populations of storks (Patnaik et al., 1970; Fabian et al., 1979; Poonswad et al., 1992; Höfle et al., 2003).

Since 2009 we have performed post-mortem examinations on free-ranging birds which died after being admitted to wildlife rescue centers in Calabria, southern Italy as part of a long-term project studying taxonomic, ecological and pathological features of helminth parasites in avian hosts (Mutafchiev et al., 2010; Santoro et al., 2010, 2011, 2012a, $2012 b)$. This short communication describes a case of massive infection by C. ferox associated with fatal cachexia in a white stork.

\section{Materials and methods}

On July 24, 2012, a debilitated white stork was found in Cassano municipality, Cosenza Province. He was brought to the Wildlife Rescue Center in Rende (Cosenza Province) where he died approximately 2 hours after admission. A complete radiographic examination was performed. The stork was weighed and detailed postmortem examination was performed to assess the cause of death. During necropsy examination, the trachea, lungs, air sacs, kidneys, spleen, liver, gallbladder, and the whole digestive tract of bird including oesophagus, stomach and intestine (duodenum, jejuno-ileum, ceca, and cloaca) were examined and helminths were collected, counted and identified. Digeneans were washed in saline solution, fixed in $70 \%$ ethanol, stained with Mayer's acid carmine, and mounted in Canada balsam for identification at light microscopy. Specimens of C. ferox are deposited in the Natural History Museum, London (Accession number: NHMUK 2013.4.18.1-3). Tissue samples were fixed in $10 \%$ neutral buffered formalin, embedded in paraffin, sectioned at $6 \mu \mathrm{m}$, and stained with haematoxylin and eosin. Sections were also stained with Brown and Brenn Gram's stain and Ziehl-Neelsen methods to detect bacteria and acid-fast organisms, respectively.

\section{Results and discussion}

The white stork was a cachectic sub-adult male weighing $2045 \mathrm{~g}$ and had brown watery diarrhea. A recent exposed 


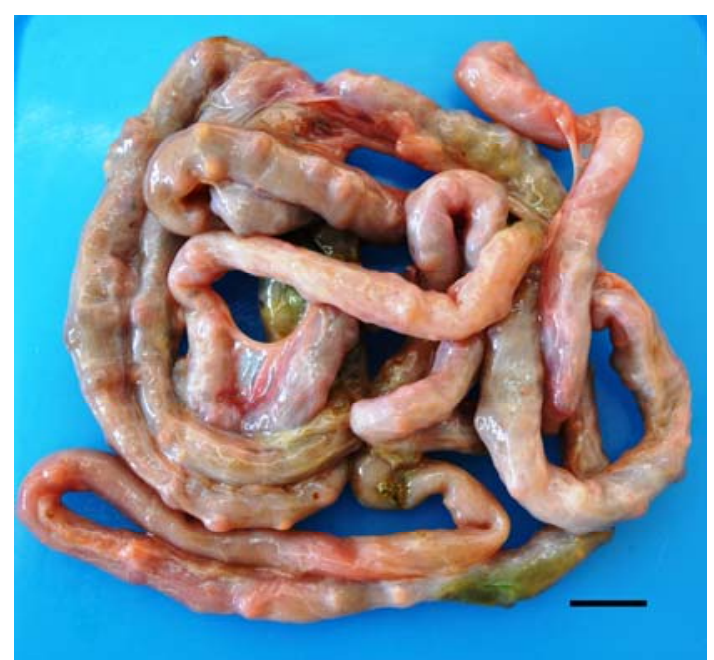

Fig. 1. Nodular enteritis associated with massive Chaunocephalusferoxinfection in a white stork(Ciconiaciconia) from southern Italy. Note that most of the serosal adherences were removed to make the nodules more visible. $B a r=1 \mathrm{~cm}$.

fracture of the right tarsometatarsus was found. No gunshot wounds were visible by radiological examination nor skin lesions due to gunshot wound penetration. The intestines had numerous adhesions associated with serosal yellow circular nodular lesions ranging from 0.2 to $0.4 \mathrm{~cm}$ in diameter throughout the duodenum, jejuno-ileum and ceca (Fig. 1). The corresponding interior mucosal surface of the nodules showed smaller brown spots with a small central ulcer containing flukes about $0.5 \mathrm{~cm}$ protruding into the intestinal lumen (Fig. 2). When the nodules were incised, usually a single or rarely two flukes were obtained. Flukes from lesions were identified as $C$. ferox (Patnaik et al., 1970), and no other parasites were found in the stork. A total of 545 specimens of $C$. ferox were found inside nodules, attached by collar spines of the cephalic extremity to the intestinal mucosal surface or free in the intestinal lumen. Apart from nodular enteritis with massive C. ferox infestation, no other abnormalities were detected on postmortem examination.

Histopathological examination of intestinal nodules confirmed sections of flukes inside granulomatous lesions along the whole intestinal tract. Morphological features of fluke sections were compatible with those of $C$. ferox extracted from granulomas or found in the intestinal lumen (Fig. 3). Histologically, at the site of fluke penetration, there was traumatic destruction of tissues with hemorrhages and increased thickness of mucosa, submucosa and muscular layer. Flukes were associated with an inflammatory infiltrate composed of heterophils, lymphocytes, and histiocytes with necrosis of the muscular layer around the parasite (Fig. 4). Apparently older lesions were characterized by the accumulation of necrotic material, degenerate heterophils and cellular debris. Lesions on the duodenal mucosa in most cases caused loss of duodenal villi and necrosis, while intestinal crypts showed enlargement due to necrotic processes caused by the parasitic infection.

Chaunocephalus ferox is an intestinal parasite of birds reported mainly in Ciconiiformes including black storks (Ciconia nigra), white storks, bitterns (Botaurus stellaris), black-necked storks (Xenorhynchus asiaticus), and Asian open-billed storks (Anastomus oscitans) (Skrjabin, 1956; Poonswad et al., 1992; Höfle et al., 2003; Natural History Museum, London, 2013). It has a cosmopolitan distribution being reported from Armenia, Czechoslovakia, Hungary, India, Italy, Japan, Poland, Spain, Thailand, Ukraine, and USSR (Patnaik et al., 1970; Höfle et al., 2003; Natural History Museum, London, 2013). Cercariae of C. ferox are found in snails and metacercariae in amphibians and fish respectively. Adult parasites are found in the intestinal crypts of birds from where they eliminate the eggs in the intestinal lumen of the host through an operculum (Kostadinova, 2005).

Poonswad et al. (1992) suggested that the pathogenicity of $C$. ferox may depend on the number of parasites present in the host. In that study intensity of infection varied from 2 to 180 in 57 of $71(80 \%)$ free-ranging Asian open-billed storks captured in Thailand (Poonswad et al., 1992). They hypothesized that mechanical damage caused by the presence of the large nodular lesions was responsible for debilitation found in 4 storks which were more heavily infected. Those lesions resulted in malnutrition following an inability to absorb nutrients from food. Patnaik et al. (1970) reported that 7 of 10 Asian open-billed storks found dead at Nandankanan Zoo (India), were infected with $C$.

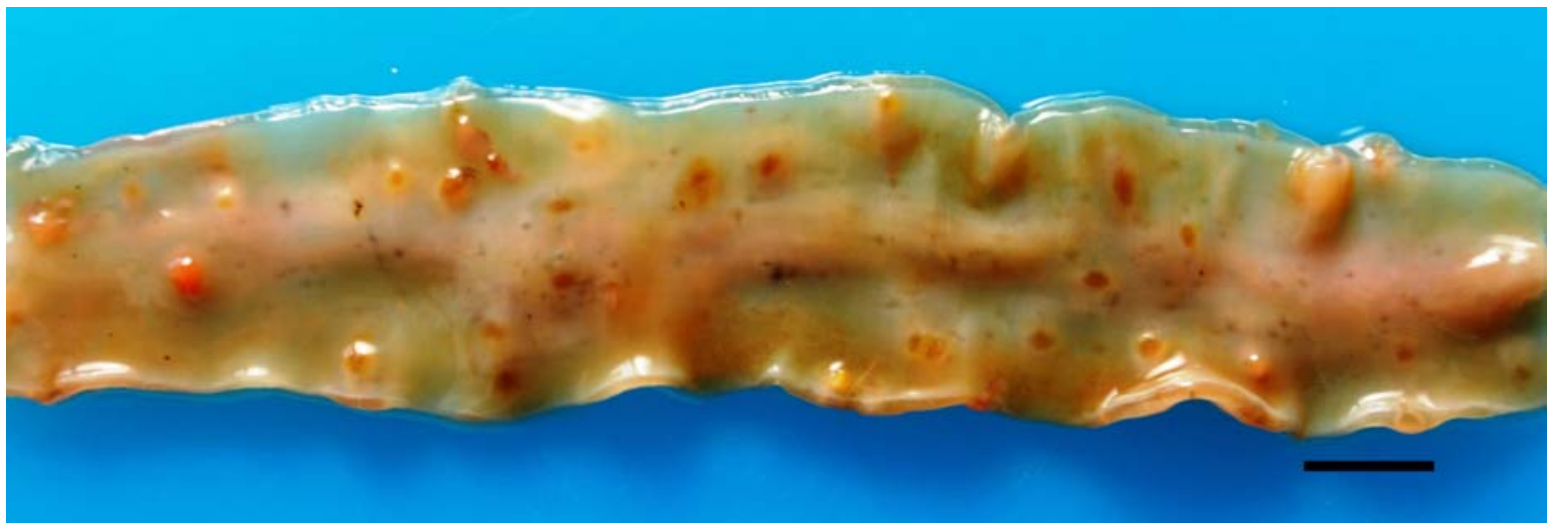

Fig. 2. Intestinal mucosal surface. Note the brown spots corresponding to nodular lesions visible on the serosal surface of Fig 1. Free flukes are also present. Bar $=1 \mathrm{~cm}$. 


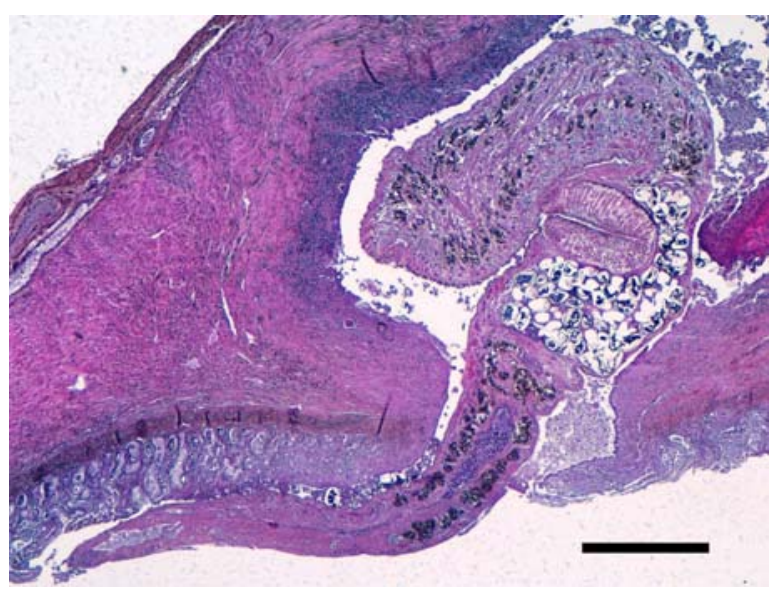

Fig. 3. Sagittal section of a mature specimen of Chanocephalus ferox coiled in intestinal nodular lesion. Posterior extremity of fluke is protruding in the intestinal lumen. $\mathrm{Bar}=1 \mathrm{~mm}$.

ferox and had shown signs of diarrhea, listlessness, loss of appetite and convulsion before death. In Hungary, a cachetic young wild stork that died within 3 days after admission to the Zoological Garden in Budapest showed a massive infection by $C$. ferox that was considered the cause of admission and subsequent death (Fabian et al., 1979).

Parasitic infection in free-ranging birds appear to cause little distress to healthy individuals, but helminths can lead to serious health problems when massive infections are combined with other factors, or occur at times of stress (Krone \& Cooper, 2002; Okulewicz \& Sitko, 2012; Santoro et al., 2012). In addition to direct effects induced by known pathogenic species, helminth infections may affect flying performance and predatory effectiveness, as well as predisposing to secondary trauma (Illescas-Gomez et al., 1993; Coulson et al., 2010; Santoro et al., 2010; Okulewicz \& Sitko, 2012). The large number of specimens of $C$. ferox reported in the white stork from southern Italy, and the resulting intestinal pathological changes probably inhibiting the absorption of nutrients, suggest an important role of this digenean on causing the cachetic status and eventual death of the bird. The recent traumatic lesion found on the tarsometatarsus may have been secondary to the cachetic status and inability to fly. This represents the first described case of chaunocephalosis in Italy.

\section{Acknowledgements}

We thank the Centro Italiano Protezione Rapaci (CIPR) in Rende (Cosenza) for permission to use the white stork carcass, and the Istituto Zooprofilattico Sperimentale del Mezzogiorno for supporting this study. The first draft of manuscript was improved by the comments from John Mike Kinsella and Thierry Work.

\section{References}

BIRD LIFE INTERNATIONAL (2012): Ciconia ciconia. In: IUCN 2012. IUCN Red List of Threatened Species. Re-

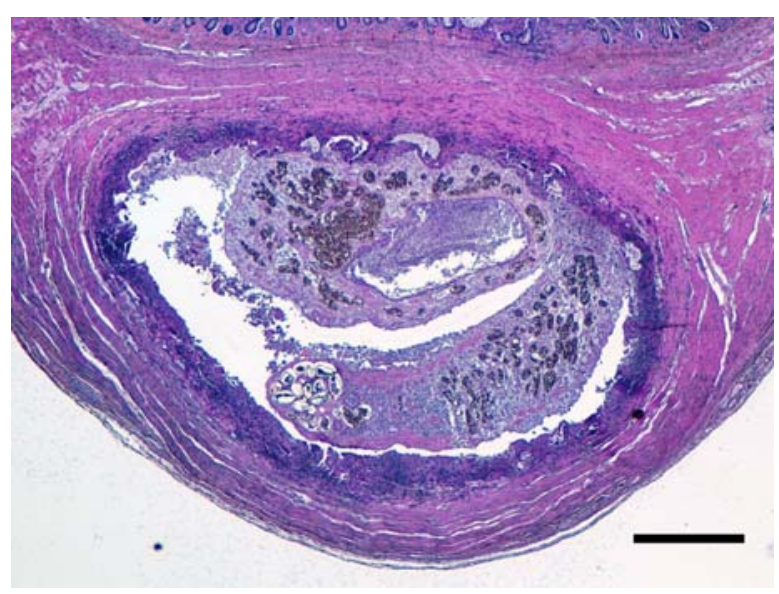

Fig. 4. Intestinal nodular lesion. Note the necrosis of muscular layer around the fluke. $\mathrm{Bar}=1 \mathrm{~mm}$.

trieved December 05, 2012 from http://www.iucnredlist.org Coulson, J., TAFT, S. J., Coulson, T. D. (2010): Gastrointestinal parasites of the swallow-tailed kite (Elanoides forficatus), including a report of lesions associated with the nematode Dispharynx sp. J. Raptor Res., 44: 208 - 214. DOI: 10.3356/JRR-09-71.1

FABIAN, L. G., Borosand, G., JANISCH, M. (1979): Verluste durch Egelbefall bei Weißstörchen (Ciconia ciconia) im Zoo Budapest. In: IPPEN, R., SCHRÖDER, H. D. (Eds) Erkrankungen der Zootiere. Berlin, Germany: Akademia Verlag, pp. $253-255$

HöFle, U., Krone, O., Blanco, J. M., Pizarro, M. (2003): Chaunocephalus ferox in free-living white storks in central Spain. Avian Dis., 47: 506 - 512. DOI: 10.1637/0005-2086(2003)047[0506:CFIFWS]2.0.CO;2

Illescas-Gomez, M. P., RODRÍGUEZ, M., ArANDA, F. (1993): Parasitation of falconiform, strigiform and passeriform (Corvidae) birds by helminths in Spain. Res. Rev. Parasitol., 53: $129-135$

Kostadinova, A. (2005): Family Echinostomatida Looss, 1899. In: Jones, A., BraY, R. A., GiBSON, D. I. (Eds) Keys to the Trematoda. Volume 2. London, UK: CABI Publishing and The Natural History Museum, pp. 9-64

Krone, O., CoOper, J. E. (2002): PARAsitic Disease. IN: COOPER, J. E. (Ed) Birds of Prey. Health and Diseases. Iowa, $3^{\text {nd }}$ Edition, Iowa State Press, pp. $105-120$

Mutafchiev,Y., Santoro, M., GeorgieV, B. B. (2010): Parachordatortilis n. gen. (Spirurida, Acuariidae), with a redescription and a new record from Italy of $P$. mathevossianae (Petrov\&Chertkova, 1950) n. comb., a parasite of Falco tinnunculus (Aves, Falconiformes). Syst. Parasitol., 76: 191-197. DOI: 10.1007.s11230-010-9243-1

NATURAL History Museum, LONDON U. K. (2013): Host parasite database. Retrieved January 5, 2013 from http:// www.nhm.ac.uk/research-curation/scientific-resources/ taxonomy-systematics/host-parasites/database/index.jsp OKulewicz, A., SitKo, J. (2012): Parasitic helminthes probable cause of death of birds. Helminthologia, 49 (4): 241 - 246. DOI: 10.2478/s11687-012-0045-7

PATNAIK, M. M., RAO, A. T., ACHARJYO, L. N., MOHANTY, 
D. N. (1970): Notes on a nodular disease of the intestine of the open-billed stork (Anastomus oscitans) caused by Chaunocephalus ferox. J. Wildl. Dis., 6: $64-66$

Poonswad, P., Chatikavanis, P., Thamavit, W. (1992):

Chaunocephalosis in a wild population of Asian openbilled storks in Thailand. J. Wildl. Dis., 28:460 - 466

SAntoro, M., TriPePI, M., Kinsella, J. M., PANEBIANCO, A., Mattiucci, S. (2010): Helminth infestation in birds of prey (Accipitriformes and Falconiformes) in southern Italy. Vet. J., 186: 119 - 122. DOI: 10.1016/j.tvj1.2009.07.001 Santoro, M., Mattiucci, S., Kinsella, J. M., Aznar, F. J., Pellegrino, F., Giordano, D., Castagna, F., NASCETTI, G. (2011): Gastrointestinal helminth community of the Mediterranean gull (Ichthyaetus melanocephalus) in southern Italy. J. Parasitol., 97: 364 - 366. DOI: $10.1645 / \mathrm{GE}-2602.1$
Santoro, M., Kinsella, J. M., Galiero, G., DegliUberti, B., AzNAR, F. J. (2012a): Helminth community structure in birds of prey (Accipitriformes and Falconiformes) in southern Italy. J. Parasitol., 98: 22 - 29. DOI: $10.1645 / \mathrm{GE}-2924.1$

Santoro, M., Mattiucci, S., Nascetti, G., Kinsella, J. M., Di Prisco, F., Troisi, S., D’Alessio, N., Veneziano, V., AzNAR, F. J. (2012b): Helminth communities of owls (Strigiformes) indicate strong biological and ecological differences from birds of prey (Accipitriformes and Falconiformes) in southern Italy. PlosOne, 7 (12): e53375. DOI: 10.1371/journal.pone.0053375

SKRJABIN, K. J. (1956): The trematodes of animal and man. Essentials of trematodology. Moskau, Leningrad, Academy of Science of the USSR

ACCEPTED SEPTEMBER 2, 2013 